\title{
Differential Effects of Isoproterenol on the Canine Atrial Action Potential in the Presence of Carbachol or Nicorandil
}

\author{
Toshihiko IIJIMA, Masao ENDOH* and Norio TAIRA \\ Department of Pharmacology. Tohoku University Schoo! of Medicine, \\ Seiryo-machi, Sendai 980, Japan \\ * Department of Pharmacology, Yamagata University School of Medicine. \\ Zao-iida, Yamagata 990-23. Japan
}

Accepted March 30, 1987

\begin{abstract}
In canine atrial muscles, carbachol and nicorandil hyperpolarized the resting membrane potential and shortened the action potential duration. In the presence of carbachol or nicorandil, isoproterenol further hyperpolarized the resting membrane potential and shortened the action potential duration. Isoproterenol significantly increased the plateau duration in the presence of nicorandil, but further abbreviated it in the presence of carbachol. This increase in the plateau duration by isoproterenol in the presence of nicorandil probably reflects the increase in the slow inward current.
\end{abstract}

It has been shown that in atrial muscles. stimulation of muscarinic receptors causes a hyperpolarization of the resting membrane potential, a decrease in the duration of the action potential, and a significant decrease in developed tension (1). The explanation for all of these changes is based on the finding that muscarinic antagonists selectively increase the membrane permeability to potassium ions. The decrease in the slow inward current induced by muscarinic agonists is considered to be a consequence of the increase in potassium conductance (2). These effects of muscarinic agonists have been termed the 'direct' effect, and the negative inotropic effect of a muscarinic agonist in cardiac muscles previously stimulated by a beta-adrenergic receptor agonist has been termed the 'indirect' effect. We have previously reported that nicorandil decreases the action potential duration and the contractile force in atrial muscles; the negative inotropic effect of nicorandil is ascribed to increasing potassium conductances of the cardiac cell membrane without mediation through muscarinic receptors (3). The negative inotropic effect of nicorandil was restored by isoproterenol, while that by carbachol was not. The difference has been ascribed to the obser- vation that carbachol but not nicorandil decreased the isoproterenol-induced elevation of cAMP level (4). The present experiments were carried out to examine the interaction between isoproterenol and carbachol or nicorandil at the membrane potentials of atrial muscles.

Mongrel dogs of either sex, weighing 5-12 $\mathrm{kg}$. were anesthetized with sodium pentobarbital $(30 \mathrm{mg} / \mathrm{kg}$, i.v.). The hearts were rapidly excised and placed in cold (about $4{ }^{\circ} \mathrm{C}$ ) Tyrode's solution equilibrated with $95 \%$ $\mathrm{O}_{2}$ and $5 \% \mathrm{CO}_{2}$. The left atrial muscle fiber bundle, less than $1 \mathrm{~mm}$ in diameter and 3-5 $\mathrm{mm}$ in length, was dissected and pinned to the bottom of a tissue chamber $(3 \mathrm{ml}$ in volume). The preparation was superfused at a rate of $7 \mathrm{ml} / \mathrm{min}$ with Tyrode's solution containing $(\mathrm{mM}): \mathrm{K}^{+}, 2.7: \mathrm{Na}^{+}, 149.3: \mathrm{Ca}^{2+}, 1.8$; $\mathrm{Mg}^{2+}, 1.0 ; \mathrm{Cl}^{-}, 145.3 ; \mathrm{HCO}_{3}{ }^{-}, 11.9 ; \mathrm{H}_{2} \mathrm{PO}_{4}{ }^{-}$. 0.4 ; and dextrose, 5.5, equilibrated with the mixed gas. The $\mathrm{pH}$ of the bathing solution ranged from 7.2 to 7.4 . Tissue bath temperature was maintained at $37 \pm 0.5^{\circ} \mathrm{C}$. The preparation was stimulated at a rate of $0.5 \mathrm{~Hz}$ with rectangular pulses of $0.5 \mathrm{msec}$ duration and voltage about twice the threshold (10-15 $\checkmark)$ through bipolar platinum electrodes and was equilibrated for at least $60 \mathrm{~min}$ after 
excision. Membrane potentials were recorded with glass microelectrode filled with $3 \mathrm{M} \mathrm{KCl}$ and having resistances of 15-20 meg-ohm. A direct-current preamplifier (WPI, model 707) was used to record membrane potentials. Membrane potentials and the maximum rate of rise obtained by electrical differentiation of the action potential were displayed on an oscilloscope (Nihon Kohden, VC-9) and photographed on $35 \mathrm{~mm}$ film. Values are given in terms of the meantS.E.M. The difference between mean values was analyzed with the paired Student's $t$-test. A P value of smaller than 0.05 was considered to be significant.

Carbachol $(0.3 \mu \mathrm{M})$ hyperpolarized the resting membrane potential and markedly shortened the action potential durations measured at the $-20 \mathrm{mV}$ and $90 \%$-repolarization levels (Fig. 1B). Under this condition. isoproterenol (1 $\mu \mathrm{M})$ further hyperpolarized the resting membrane potential and shortened the action potential duration at both levels (Fig. 1C).

Nicorandil (0.3 mM) also hyperpolarized the resting membrane potential and very markediy shortened the action potential duration measured at $-20 \mathrm{mV}$ and $90 \%$ repolarization level (Fig. 1F). In the presence of the drug, isoproterenol (1 $/ \mu \mathrm{M})$ also further increased the resting membrane potential and shortened the action potential duration measured at the $90 \%$-repolarization level. However, the action potential duration measured at the $-20 \mathrm{mV}$ level was very slightly but significantly increased by isoproterenol (Fig. 1G). Summarized results obtained in these experiments are shown in Table 1.

Beta-adrenoceptor stimulation of the myocardium increases the slow inward current and consequently changes the action potential configuration. The slow inward calcium current has been implicated in production of the plateau phase of the action potential in atrial (5) and ventricular (6) muscles. The effects of beta-adrenoceptor stimulation are mediated by an increase in the intraceliular CAMP (7). As carbachol probably inhibits the action of beta-adrenoceptor-mediated positive inotropic response by blocking CAMP formation (4.8), it is quite understandable that isoproterenol is unable to increase the action potential duration in the presence of carbachol. On the other hand, isoproterenol failed to restore the action potential duration but significantly increased the plateau duration even when the $\mathrm{K}^{+}$conductance is
A

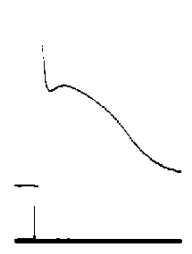

E

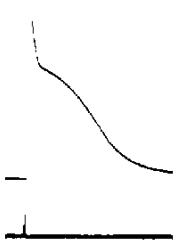

B

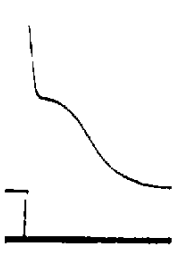

F

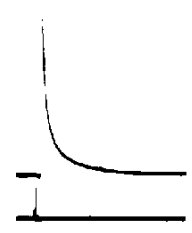

C

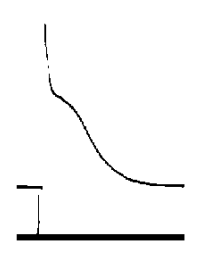

G

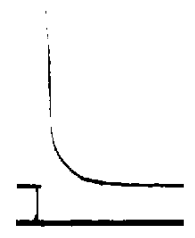

D

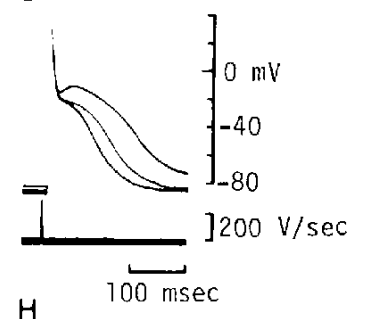

H

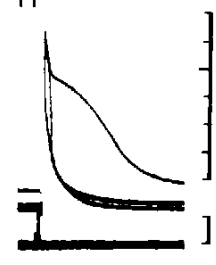

Fig. 1. Effects of isoproterenol on action potentials of the canine atrial muscles in the presence of carbachol or nicorandil. A: control; $\mathrm{B}$ : carbachol $(0.3 \mu \mathrm{M}) ; \mathrm{C}$ : isoproterenol $(1 \mu \mathrm{M})$ in the presence of carbachol; D: superposition of $A$. B and C: E: control: F: nicorandil $(0.3 \mathrm{mM})$ : $G$ : isoproterenol $(1 \mu \mathrm{M})$ in the presence of nicorandil; $H$ : superposition of $E, F$ and $G$. Records in $A-D$ and $E-H$ are obtained from single impalements. 
Table 1. Effects of carbachol and nicorandil and interaction with isoproterenol on action potentials of the canine atrial muscles

\begin{tabular}{|c|c|c|c|c|c|c|}
\hline & $N$ & $\begin{array}{l}\text { Resting potential } \\
\qquad(m \vee)\end{array}$ & $\begin{array}{c}\text { Overshoot } \\
\text { (msec) }\end{array}$ & $\begin{array}{l}\mathrm{APD}_{-20} \\
\text { (msec) }\end{array}$ & $\begin{array}{l}\mathrm{APD}_{90} \\
(\mathrm{msec})\end{array}$ & $\begin{array}{c}\dot{V} \max \\
(\mathrm{V} / \mathrm{sec})\end{array}$ \\
\hline Control & 4 & $-81 \pm 2$ & $30 \pm 2$ & $88 \pm 15$ & $211 \pm 15$ & $232 \pm 9$ \\
\hline $\begin{array}{l}\text { Carbachol } \\
\qquad(0.3 \mu \mathrm{M})\end{array}$ & & $-85 \pm 2^{*}$ & $32 \pm 1$ & $43 \pm 8^{*}$ & $146 \pm 4^{* *}$ & $253 \pm 17$ \\
\hline $\begin{array}{l}\text { Carbachol } \\
+ \text { Isoproterenol } \\
\quad(1 \mathrm{\mu M})\end{array}$ & & $-89 \pm 2^{*}$ & $29 \pm 1$ & $17 \pm 4^{*}$ & $119 \pm 4^{* *}$ & $264 \pm 21$ \\
\hline Control & 5 & $-82 \pm 1$ & $29 \pm 2$ & $97 \pm 18$ & $205 \pm 14$ & $221 \pm 7$ \\
\hline $\begin{array}{l}\text { Nicorandil } \\
\qquad(0.3 \mathrm{mM})\end{array}$ & & $-88 \pm 2^{*}$ & $26 \pm 2$ & $7 \pm 2^{* *}$ & $77 \pm 22^{* *}$ & $248 \pm 20$ \\
\hline $\begin{array}{l}\text { Nicorandil } \\
+ \text { Isoproterenol } \\
(1 \mu \mathrm{M})\end{array}$ & & $-94 \pm 1^{*}$ & $27 \pm 2$ & $14 \pm 3^{* * *}$ & $55 \pm 9^{*}$ & $289 \pm 29$ \\
\hline
\end{tabular}

$\mathrm{N}$ means the number of preparations. $A P D_{-20}$ and $A P D_{90}$ indicate the action potential duration measured at $-20 \mathrm{mV}$ and $90 \%$-repolarization level, respectively. ${ }^{*},{ }^{* *}$, and ${ }^{* * *}: P<0.05 . P<0.01$, and $P<0.001$, when a value is compared to the value immediately above it. Values are expressed as the meantS.E.M.

Recordings were done by single cell impalements.

strongly accelerated by nicorandil. This is consistent with the previous observation that nicorandil does not inhibit the isoproterenolinduced elevation of cAMP level and the negative inotropic response induced by nicorandil can be restored by isoproterenol (4). These results indicate that nicorandil can increase the $\mathrm{K}^{+}$conductance, but does not interact with the $\mathrm{Ca}^{2+}$ conductance augmented by isoproterenol. Recently, we have reported that nicorandil has no direct effects on the inward calcium current even when the inward calcium current is previously augmented by isoproterenol (9).

The plateau duration, however, was even shorter in the presence of nicorandil and isoproterenol than in the presence of carbachol and isoproterenol. This may be because the tremendous increase in potassium conductance by nicorandil has masked the augmented calcium influx through the CAMP. mediated phosphorylation increased by $150-$ proterenol. Furthermore, accumulated CAMP in the presence of nicorandil and isoproterenol would increase the capability of the sarcoplasmic reticulum to release more calcium, and this may be essential for the restoration of the contractile force by isoproterenol. It is also interesting to note that even in the presence of carbachol or nicorandil, isoprotereno! further hyperpolarized the resting membrane potential. This effect is produced not by activation of the $\mathrm{Na}-\mathrm{K}$ ATPase activity but by activation of the catecholamine-induced increase in potassium conductance which is different from the background potassium conductance $(10,11)$ The present results also indicate that the catecholamine-induced potassium conductance is not related to the intracellular calcium or CAMP concentration because in the presence of carbachol, intracellular calcium or CAMP concentration cannot be increased by isoproterenol (4).

Acknowledgments: This work was partly supported by a Grant-in-Aid for Scientific Research from the Ministry of Education. Science and Culture. Japan. We are grateful for the generous supply of nicorandil by Chugai Pharmaceutical Co., Tokyo. Japan.

\section{Referenses}

1 Burgen, A.S.V. and Terroux, K.G.: On the negative inotropic effect in the cat's auricle. J. Physiol. (Lond.) 120, 449-464 (1953)

2 lijima, T.s Irisawa, $H$. and Kameyama, M.: Membrane currents and their modification by acetylcholine in isolated single atrial cells of the guinea-pig. J. Physiol. (Lond.) 359, 485-501 (1985)

3 Yanagisawa, T, and Taira, N.: Effect of 2-nicotinamidethyl nitrate (SG-75) on the membrane potential of the left atrial muscle fibres of the dog: 
increase in potassium conductance. Naunyn Schmiedebergs Arch. Pharmacol. 312, 69-76 (1980)

4 Endoh, M. and lijima, T.: Effects of nicorandil and its interaction with isoproterenol on force of contraction and cyclic nucleotide levels of canine atrial muscle: Comparison with carbachol. J. Cardiovasc. Pharmacol. 5, 878-882 (1983)

5 Pappano, A.J.: Calcium-dependent action potentials produced by catecholamines in guinea pig atrial muscle fibers depolarized by potassium. Circ. Res. 27, 379-390 (1970)

6 Beeler, G.W., Jr. and Reuter, H.: Voltage clamp experiments on ventricular myocardial fibres. J. Physiol. (Lond.) 207, 165-190 (1970)

7 Tsien, R.W., Giles, W. and Greengard, P.: Cyclic AMP mediates the effects of adrenaline on cardiac Purkinje fibres. Nature New Biol. 240,
$181-183(1972)$

8 Endoh, M., Maruyama, M. and lijima, T.: Attenuation of muscarinic cholinergic inhibition by islet-activating protein in the heart. Am. J. Physiol. 249, H309-H320 (1985)

9 lijima, T. and Taira, N.: Modification by nicorandi] and carbachol of the inward calcium current in single cells of the guinea-pig heart. Tohoku J. Exp. Med. 150, 475-479 (1986)

10 Gadsby, D.C.: $\beta$-Adrenoceptor agonists increase membrane $K^{+}$conductance in cardiac Purkinje fibres. Nature 306, 691-693 (1983)

11 Boyden, P.A., Cranefield, P.F. and Gadsby, D.C.: Noradrenaline hyperpolarizes cells of the canine coronary sinus by increasing their permeability to potassium ions. J. Physiol. (Lond.) 339, 185$206(1983)$ 